\title{
Effects of Patulin Treatment on Zebrafish (Danio rerio) Internal Organs
}

\author{
TIGRAN-LUCIAN MANDALIAN ${ }^{1 *}$, DRAGOMIR COPREAN ${ }^{1}$, AURELIAN-SORIN PASCA ${ }^{2}$ \\ ${ }^{1}$ University Ovidius of Constanța, Faculty of Natural Sciences and Agricultural Sciences, 1 Alley of the University, 900470 , \\ Constanta, Romania \\ ${ }^{2}$ Ion Ionescu de la Brad University of Agricultural Sciences and Veterinary Medicine of Iasi, 3 Mihail Sadoveanu Alley, \\ 700490, Iasi, Romania
}

\begin{abstract}
Patulin is a common contaminant of many food products which are part of humans or animals daily nutrition: fruits and fruit products, cereals, diary products and sausages. In the present study, adult zebrafish were divided in 2 groups: Control and patulin-treated group which was exposed to patulin $(70 \mu \mathrm{g} / \mathrm{L})$ for 7 days. Histological alterations of the control and patulintreated group were examined and compared, with emphasis on liver, kidney, pancreas, intestine, brain and myocardium. While the Control group had no histological alterations, the patulin-exposed zebrafish show severe hepatocyte alteration, medium to severe degeneration of urinary epithelium, enterocytes hyalinosis, partial coagulation necrosis of the Langerhans islets and myocardial edema.
\end{abstract}

Keywords: patulin, nephrotoxicity, hepatotoxicity, pancreas, intestine, myocardium

Patulin (4-hydroxy-4H-furo[3,2c]pyran-2[6H]-one) is produced by over 60 species of fungi, the most important being Penicillium expansum, P. patulum, P. crustosum, P. roqueforti, P. claviforme, Aspergillus giganteus, A. terreus, A. clavatus, Saccharomyces vesicarium, Alternaria alternata, Byssochlamys nivea, B. fulva [1].

This mycotoxin contaminates many food products which are part of humans or animals daily nutrition: fruits, fruit juices, jams, seeds, alcoholic drinks, cereals and pastry products, diary products and sausages [1]. Patulin concentration in apple juices from the Romanian market ranged between $0.7-101.9 \mu \mathrm{g} / \mathrm{l}, 6 \%$ of the analysed samples exceeding the 50 $\mu \mathrm{g} / \mathrm{l}$ maximum limit set by the European Comission [2].

This mycotoxin alterates intestinal mucosa barrier [3], has toxic effects on the colon [4] and jejunal mucosa [5]. Patulin administration elevates hepatic enzymes, leads to hepatocytes vacuolation, cell necrosis, pyknosis, karyomegaly or nuclear degeneration [6] and fatty degeneration [7].

Literature highlights the effects on excretory system of Danio rerio embryos: slight morphological alterations of glomeruli and pronephric tubules and a reduction in glomerular filtration rate [8].

Mammals were affected by inflammation and degeneration of the Bowman capsule, glomeruli and nephron tubules [7]. Patulin also induced erythrocyte apoptosis [9], renal cells apoptosis [10] and oxidative damage in the brain [11]. Patulin inhibited the activity of some antioxidant enzymes (CAT, GPX) while increasing the level of reactive oxygen species (MDA) [12].

While most histological tests (involving mycotoxins) have been conducted on zebrafish embryos, this study aims to evaluate the histological effects of patulin exposure $(70 \mu \mathrm{g} / \mathrm{L})$ on the internal organs of adult zebrafish (Danio rerio). The treatment dose exceeds the maximum limit set by the European Comission.

\section{Experimental part}

\section{Chemicals}

Patulin was obtained from Romer Labs Diagnostic GmbH (Tulln, Austria).

Animals and experimental design

Adult zebrafish (Danio rerio) were kept in aquariums for 7 days to accommodate to laboratory conditions. After this period, the animals were divided in 2 groups: Control and Patulin group ( $70 \mu \mathrm{g} / \mathrm{L})$. Patulin was administered daily, by immersion, for 7 days.<smiles>O=C1C=C2C(=CCOC2O)O1</smiles>

Fig. 1.Chemical structure of patulin

\footnotetext{
*email: tigranmandalian@gmail.com
} 


\section{Histological examination}

For the histological examination, immediately after euthanasia, the fish were fixed in formaldehyde solution $10 \%$ for 48 hours. Afther that, for demineralization, the fish were immersed in Bouin solution for 24 hours. For the sectioning, the fish were fully embedded in paraffin, using histologic processor Leica TP 1020. Starting from the median axis, $5 \mu \mathrm{m}$ thick histological sections were made longitudinally. Masson's trichromic stain (hematoxylin - eosin - methylene blue) was used. Histological examination was made under a light microscope Leica DM 750, the images being captured with a Leica HD 5 megapixels digital camera. Histological alterations of the control and patulin-treated group were examined and compared, with emphasis on liver, kidney, pancreas, intestine, brain and myocardium.

\section{Results and discussions}

After examining the zebrafish from the Control group, we observed there were no histological alterations of the liver, kidney, intestine, pancreas or myocardium.

Patulin exhibits toxic effects on zebrafish liver. The histological examinations reveal severe hepatocyte alteration with toxic etiology (Fig. 2). The hepatocytes are swollen, with vacuolated cytoplasm and hyperhydrated nucleus. Triglyceride loading (empty intracytoplasmic vacuoles) is also present.

The vacuolation of the hepatocytes after patulin exposure is confirmed by a study on rats [6]. Vacuolization leads to the dysfunction of macropinocytosis, endocytosis, and autophagy but is not the cause of cell death [13]. Vacuolization is considered a side effect of cytotoxic factors and a mechanism that can reduce stress and increase the cell survival potential [13].

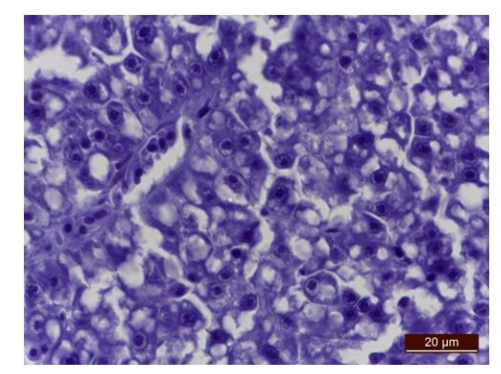

Fig. 2. Severe hepatocyte alteration. Swollen hepatocytes with vacuolated cytoplasm and hyperhydrated nucleus. Triglyceride loading is also present. Liver. Masson's trichrome stain

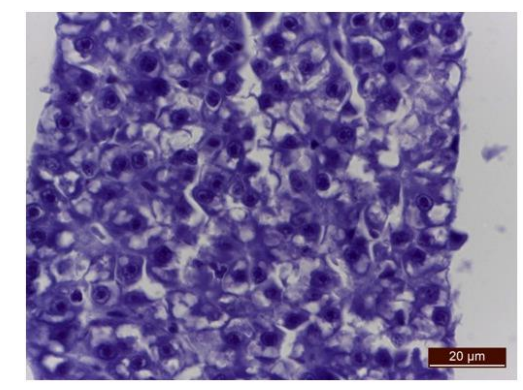

Fig. 3. Hydropic and lipidic dystrophy of hepatocytes. Hyperhydrated cytoplasm and nucleus. Cytoplasmic lipid accumulation.

Liver. Masson's trichrome stain

In the liver

of patulin-treated zebrafish, we also observed the loss of hepatocyte integrity due to broken cell membranes and disorganization of the cytoplasm. Hepatocyte damage and loss of cell outline has also been observed in mice, after 2 weeks of patulin treatment [14].

The hepatocytes of the Patulin-treated group showed hydropic and lipid dystrophy (Fig. 3). Some cells have hyperhydrated cytoplasm and nucleus, in other cells there is a cytoplasmic lipid accumulation. Also, in the case of mice, patulin exposure led to fatty degeneration [7]. After one week of patulin exposure, there is a difference between mice hepatocytes, which had granular cytoplasm [14], and the hyperhydration observed in zebrafish hepatocytes.

In the liver of patulin-treated zebrafish there were no signs of hepatocyte necrosis, sinusoids dilation/irregularities, nuclear abnormalities as in the case of patulin-treated mice [7] or rats [6].

Lymphocyte infiltration in the liver of patulin-exposed rats and mice [15] was absent in patulin-treated zebrafish.

Nephrotoxic effects are characterized by medium to severe degeneration of urinary epithelium, nephrocytes swelling, cytoplasm vacuolation and nuclear hyperhydration (Fig. 4). Some nephrocytes lose integrity by detachement from the basement membrane of the urinary tubule. In contrast with a study on mice [10], renal cells apoptosis was not present.

Patulin leads to degenerative processes of the mice nephron tubules, Bowman capsule and glomeruli [7]. The morphological alterations of the glomeruli and pronephric tubules shown in the case of patulin-exposed zebrafish embryos [8] sustain the similarity between the effects on zebrafish and rodents.

The morphological alterations of the glomeruli is followed by a reduction of the filtration rate [8], thus we can make the assumption that glomeruli degeneration also alters the filtration rate. 
Interstitial capillaries of the patulin-treated zebrafish are overloaded with erythrocytes, thus leading to a medium congestion, while kidney of the patulin treated mammals showed capillary lesions [16-18]. Also, a more recent study states that patulin exposure leads to hemorrhagic lesions of the mice kidney [7].

Marine fish (D. labrax) also showed congestion of the kidneys after exposure to a wide-spread mycotoxin - Ochratoxin A ( $(2 S)$-2-[[(3R)-5-chloro-8-hydroxy-3-methyl-1-oxo-3,4-dihydroisochromene-7-carbonyl]amino]-3-phenylpropanoic acid) $[19,20]$.

In patulin-treated group kidneys, there is an inflammatory component represented by monocyte infiltration of the urinary epithelium, while in patulin-treated rats there was a lymphocyte infiltration [15]. The inflammatory cell infiltration is also present in the kidney of mice exposed to patulin [7].

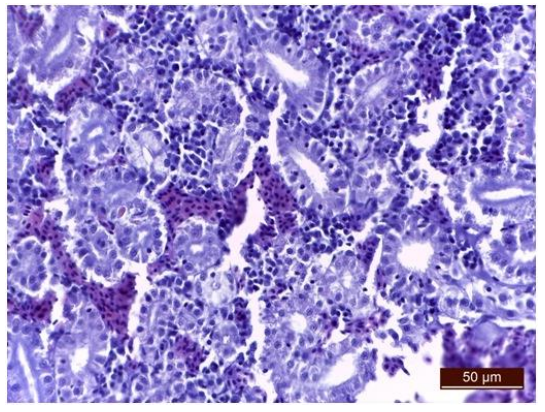

Fig. 4. Medium to severe degeneration of urinary epithelium: nephrocytes swelling, cytoplasm vacuolation, nuclear hyperhydration, nephrocytes detachement from the basement membrane. Interstitial capillaries congestion, monocyte infiltration of the urinary epithelium. Kidney. Masson's trichrome stain

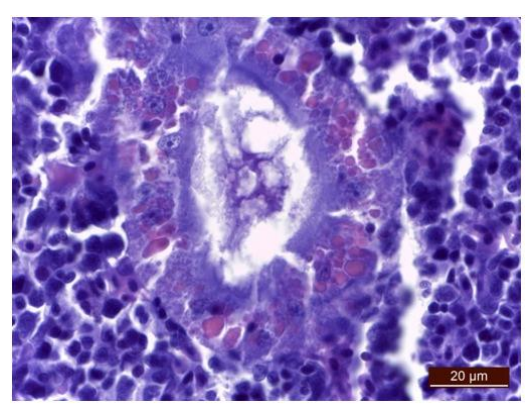

Fig. 5. Smooth hyaline casts in the nephrocytes cytoplasm indicate tubular epithelium hyalinosis. Kidney. Masson's trichrome stain

In the nephrocytes, it is observed the presence of large, perfectly spherical, vitreous casts with homogenous structure, appearing acidophilic in Masson's trichrome stain (Fig. 5). The breaking of the apical pole of the cells is followed by the formation of hyaline casts in the renal tubule lumen. The presence of increased numbers of hyaline casts can lead to kidney failure.

Our results are in line with a study on rats and mice [15], which showed that the urine of the patulin-treated rats contained granular and hyaline casts.

Hyalinosis of the tubular epithelium (Fig. 5 and Fig. 6) does not imply a nephrocyte lesion. The cause is an active pinocytosis of the proteins (from the filtered primary urine) in all pathological conditions which imply severe proteinuria or nephrotic syndrome. Normally, protein absorption is followed by formation of heterophagolysosomes and protein degradation to aminoacids which are returned to blood flow. The accumulation of hyaline globules indicates the saturation of the physiological mechanism.

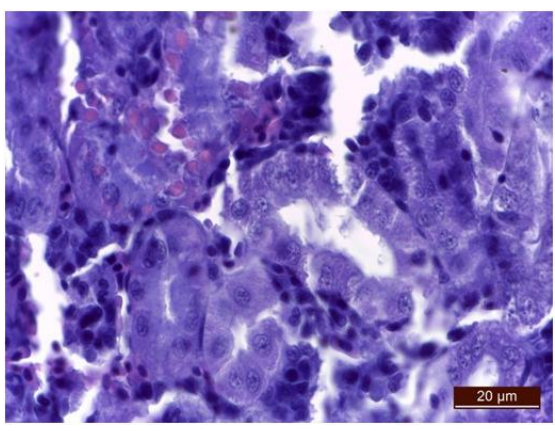

Fig. 6. Tubular hyalinosis. Kidney. Masson's trichrome stain

Rev. Chim. $71 \bullet$ no. $2 \bullet 2020$ https://revistadechimie.ro

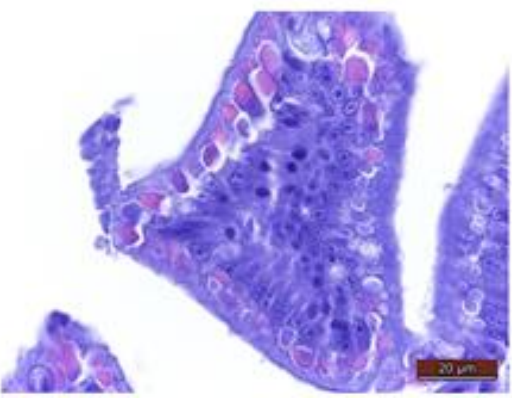

Fig. 7. Enterocytes hyalinosis - vitreous casts in the cytoplasm. Intestine. Masson's trichrome stain 
Enterocytes hyalinosis (Fig. 7) - vitreous casts in the cytoplasm imply a transcellular transport deficiency (from the enterocyte brush border to basal pole of the cell) of the nutrients from the intestinal content. This can lead to malabsorption syndrome.

Malabsorption due to patulin exposure is in line with previous studies on rodents and swines. In rodents, patulin impairs the intestinal absorption due to its toxic effects on gastro-intestinal mucosa: ulcerations, hemorrhagic lesions, cellular pyknosis, necrosis, eosinophils agglomeration [15] and inflammatory processes [21]. The effects of patulin on swine intestine (decrease in density of the goblet cell, intestinal villi and crypts) [5] can also lead to malabsorption.

The endocrine pancreas of the patulin-treated zebrafish is affected by partial coagulation necrosis of Langerhans islets (Fig. 8). This will alter the production of pancreatic endocrine hormones (insulin, glucagon, somatostatin) and fish metabolism.

Literature states that other mycotoxin, ochratoxin A, leads to tissue damage of the fish $(O$. niloticus $)$ pancreatic islets [22].

Patulin-treated group had no signs of exocrine pancreas alterations, as is the case of I. punctatus fed with ochratoxin A [23]. Pancreatic inflammation shown in $O$. niloticus fed with aflatoxin B1 ((3S,7R)-11-methoxy-6,8,19trioxapentacyclo[10.7.0.0 $\left.0^{2,9} \cdot 0^{3,7} \cdot 0^{13,17}\right]$ nonadeca-1,4,9,11,13(17)-pentaene-16,18-dione) [24], has not been observed in patulin-treated zebrafish.

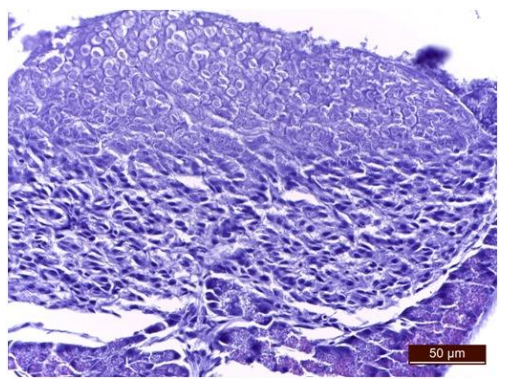

Fig. 8. Partial coagulation necrosis of the endocrine pancreas (Langerhans islets). Pancreas. Masson's trichrome stain

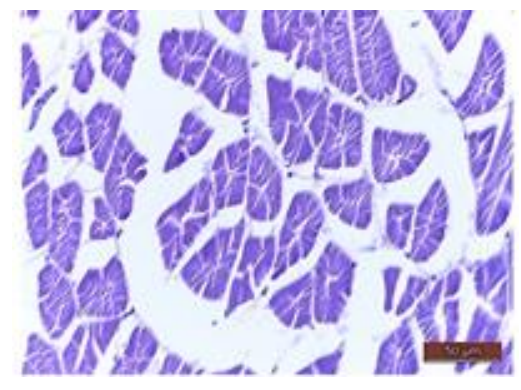

Fig. 9. Myocardial edema: clear interfibrillar spaces, swollen myocardiocytes and hyperhydrated sarcoplasm. Myocardium - cross section. Masson's trichrome stain

Patulin-treated fish showed myocardial edema marked by clear interfibrillar spaces, swollen myocardiocytes and hyperhydrated sarcoplasm (Fig. 9). These effects can lead to a decrease of the heartbeat rate.

Patulin cardiotoxicity is sustained by a study on mice [25], which showed that patulin induced oxidative stress and cell apoptosis. These effects can also lead to alterations of cardiac functions.

Other studies demonstrate the cardiotoxic effects of several mycotoxins on the structure and function of zebrafish embryos heart: pericardial edema [26-29], decrease in heartbeat rate [28, 29], diminished size of heart chambers and stacking up of cardiomyocytes [30].

\section{Conclusions}

The patulin-treated group shows histological alterations of the liver, kidney, intestine, pancreas and myocardium.

In the liver of patulin-treated zebrafish, the histological alterations are represented by swollen hepatocytes, vacuolated cytoplasm, hyperhydrated nucleus and triglyceride loading. There can also be observed a loss of cell integrity in hepatocytes due to broken cell membranes.

In the kidney of treated group it has been shown the presence of tubular epithelium hyalinosis, indicating the saturation of the physiological mechanism. The medium to severe degeneration of urinary epithelium is characterized by nephrocytes swelling, loss of integrity, cytoplasm vacuolation, nuclear hyperhydration, interstitial capillaries congestion and monocyte infiltration.

In the intestine of patulin-exposed fish it has been shown the presence of enterocytes hyalinosis. This implies a transcellular transport deficiency of the nutrients from the intestinal content.

The pancreas of the patulin-treated group showed partial necrosis of the endocrine pancreas (Langerhans islets). 
The treated group showed myocardial edema, swollen myocardiocytes and hyperhydrated sarcoplasm. This histological alterations can decrease heartbeat rate.

\section{References}

1. JOSHI, V.K., LAKHANPAL, P., KUMAR, V., International Journal of Food and Fermentation Technology, 3, no.1, 2013 , p.15.

2. OROIAN, M., AMARIEI, S., GUTT, G., Food Additives \& Contaminants: Part B, 7, no. 2, 2014, p.147.

3. MCLAUGHLIN, J., LAMBERT, D., PADFIELD, P.J., BURT, J.P., O’NEILL, C.A., Toxicology in Vitro, 23, no. 1, 2009 , p.83.

4. MOHAN, H.M., COLlinS, D., MAHER, S., WALSH, E.G., WINTER, D.C., O'BRIEN, P.J., BRAYDEN, D.J., BAIRD, A.W., Food and chemical toxicology, 50, no. 11, 2012, p.4097.

5. MAIDANA, L., GEREZ, J.R., EL KHOURY, R., PINHO, F., PUEL, O., OSWALD, I.P., BRACARENSE, A.P.F., Food and Chemical Toxicology, 98, 2016, p.189.

6. EL-SAWI, N.M., GASHLAN, H.M., YOUNES, S.H., AL-MASSABI, R.F., SHAKER, S., Life Science Journal, 9, no. 4,2012 p.1143.

7. AL-HAZMI, M.A., Toxicology and industrial health, 30, no. 6, 2014, p.534.

8. WU, T.S., YANG, J.J., YU, F.Y., LIU, B.H., Food and chemical toxicology, 50, no. 12, 2012, p.4398.

9. LUPESCU, A., JILANI, K., ZBIDAH, M., LANG, F., Cellular Physiology and Biochemistry, 32, no.2, 2013, p. 291.

10. BOUSSABBEH, M., SALEM, I.B., BELGUESMI, F., NEFFATI, F., NAJJAR, M.F., ABID-ESSEFI, S., BACHA, H., Environmental Science and Pollution Research, 23, no.10, 2016, p. 9799.

11. SONG, E., SU, C., FU, J., XIA, X., YANG, S., XIAO, C., LU, B., CHEN, H., SUN, Z., WU, S., SONG, Y., Life sciences, 109, no. 1, 2014 , p.37. 12. CIORNEA, E.T., DUMITRU, G., COPREAN, D., MANDALIAN, T. L., BOIANGIU, R.Ș., SANDU, I., HRIȚCU, L., Rev. Chim, 70, no. 3, 2019 , p. 776.

13. SHUBIN, A.V., DEMIDYUK, I.V., KOMISSAROV, A.A., RAFIEVA, L.M., KOSTROV, S.V., Oncotarget, 7, no. 34, 2016 , p. 55863.

14. GASHLAN, H.M., Journal of Applied Animal Research, 34, no.1, 2008, p.93.

15. ESCOULA, L., MORE, J., BARADAT, C., HENRY, G., BRUNEL-DUBECH, N., Annales de recherches veterinaires, 8, no. 1, 1977 , p. 41.

16. HARWIG, J., MUNRO., I. C., Can. Vet. J. 16, no. 5, 1975, p. 125.

17. STOTT, W. T., L. B. BULLERMAN., J. Milk Food Technology. 38, no. 11, 1975, p.695.

18. BULLERMAN, L.B., Journal of Food Protection, 42, no. 1, 1979, p.65.

19. EL-SAYED, Y.S., KHALIL, R.H., Food Chem. Toxicol., 47, 2009, p. 1606.

20. ANATER, A., MANYES, L., MECA, G., FERRER, E., LUCIANO, F.B., PIMPÃO, C.T., FONT, G., Aquaculture, 451, 2016 , p.1.

21. MCKINLEY, E.R., CARLTON, W.W., BOON, G.D., Food and Chemical Toxicology, 20, no. 3, 1982, p.289.

22. MANSOUR, T.A., MOHAMED, S.G., SOLIMAN, M.K., OMAR, E.A., SROUR, T.M., ZAKI, M.S., HASSAN, S.M.S., Life Science Journal, 8, no. 1,2011, p.68.

23. MANNING, B.B., ULLOA, R.M., LI, M.H., ROBINSON, E.H., ROTTINGHAUS, G.E., Aquaculture, 219, no. 1-4, 2003 , p.739.

24. CHÁVEZ-SÁNCHEZ, M.C., PALACIOS, C.M., MORENO, I.O., Aquaculture, 127, no. 1, 1994, p.49.

25. BOUSSABBEH, M., BEN SALEM, I., NEFFATI, F., NAJJAR, M.F., BACHA, H., ABID-ESSEFI, S., Journal of biochemical and molecular toxicology, 29, no. 10, 2015, p.479.

26. BAKOS, K., KOVÁCS, R., STASZNY, Á., SIPOS, D.K., URBÁNYI, B., MÜLLER, F., CSENKI, Z., KOVÁCS, B., Aquatic toxicology, 136, 2013, p.13.

27. YUAN, G., WANG, Y., YUAN, X., ZHANG, T., ZHAO, J., HUANG, L., PENG, S., Journal of Environmental Sciences, 26, no. 4,2014 , p.917. 28. VESELINOVIĆ, J.B., VESELINOVIĆ, A.M., ILIC-TOMIC, T., DAVIS, R., O'CONNOR, K., PAVIC, A., NIKODINOVIC-RUNIC, J., Bioorganic \& medicinal chemistry, 25, no. 24, 2017, p.6286.

29. MUTHULAKSHMI, S., MAHARAJAN, K., HABIBI, H.R., KADIRVELU, K., VENKATARAMANA, M., Chemosphere, 198, 2018 , p.111.

30. WU, T.S., YANG, J.J., YU, F.Y., LIU, B.H., Toxicological sciences, 136, no. 2, 2013, p.402.

Manuscript received: 5.06.2019 